\title{
ANALISIS POSTUR KERJA DENGAN METODE REBA DAN GAMBARAN KELUHAN SUBJEKTIF MUSCULOSKELETAL DISORDERS (MSDS) (PADA PEKERJA SENTRA INDUSTRI TAS KENDAL TAHUN 2017)
}

\author{
Ayu Setiorini ${ }^{1}$, Siti Musyarofah $^{2}$, Mushidah $^{3}$, Baju Widjasena $^{4}$ \\ 1,2,3 Program Studi Kesehatan Masyarakat STIKES Kendal \\ Email: ${ }^{1}$ ayusetyor171@gmail.com, ${ }^{2}$ sitimusyarofah24@gmail.com, \\ 3 hidnisa4@gmail.com \\ ${ }^{4}$ Fakultas Kesehatan Masyarakat Universitas Diponegoro

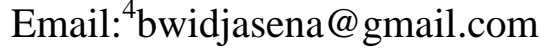

\begin{abstract}
Abstrak
Sentra Indutri Tas Kendal merupakan salah satu paguyuban didaerah Kendal yang memproduksi tas, dimana setiap aktivitas kerjanya, pekerja berisiko untuk menderita terjadinya Musculoskeletal Disorder's (MSDs) terkait dengan masalah ergonomi. Rapid Entire Body Assessment (REBA) adalah sebuah metode dalam bidang ergonomi yang digunakan secara cepat untuk menilai postur leher, punggung, pergelangan tangan, dan kaki pekerja. Penelitian dilakukan untuk mengetahui gambaran postur kerja dan gambaran keluhan subjektif $M S D$ s pada pekerja bagian pola dan gudang. Desain penelitian adalah Cross Sectional Deskriptif. Penelitian postur kerja menggunakan metode REBA dan kuesioner Nordic Body Map (NBM). Data dianalisis secara deskriptif. Hasil dari penelitian ini menunjukkan skor REBA akhir yaitu 10 pada aktifitas pembuatan pola 1 pekerja (25\%), dan skor 10 pada aktifitas gudang 1 pekerja (33\%). Keluhan subjektif MSDs terbanyak dirasakan pekerja pada bagian pinggang 6 dari 7 pekerja (86\%). Gambaran keluhan MSDs berdasarkan masa kerja pada kategori $<5$ tahun di bagian pinggang sebesar $100 \%$ dan kategori masa kerja 5-10 tahun keluhan pada leher bagian atas sebesar $80 \%$. Sehingga, diperlukan tindakan segera dalam melakukan proses kerja, perubahan alat kerja dan desain area kerja untuk mengurangi risiko ergonomi dan keluhan subjektif MSDs.
\end{abstract}

Kata kunci : Keluhan Subjektif MSD's, Pekerja, Postur kerja, REBA

\footnotetext{
ABSTRACT

Bag Industrial Centra Kendal is one of the Kendal community groups that produce bags, where each work activity, workers at risk to suffer the occurrence of Musculoskeletal Disorders (MSDs) associated with ergonomics problems. Rapid Entire Body Assessment (REBA) is a method of ergonomics used rapidly to assess the posture of the neck, back, wrist, and worker's feet. This researchto describe the work posture and the subjective complaints picture of MSDs on the workers. This research used Cross Sectional Descriptive. This research was conducted by assessing work posture using REBAmethod and
} 
questionnaire of Nordic Body Map. Data analyzed by descriptive. The results showed the final REBA score of 10 on the pattern making activity 1 worker(25\%), and score 10 on the warehouse activity of 1 worker $(33 \%)$. Subjective complaints MSDs most felt workers at the waist $86 \%$. Description of MSDs complaints based on employment in the $<5$ year category at the waist $100 \%$ and 5-10 years working period of complaints on the upper neck $80 \%$. Immediate action is required in the work process, change the work tools and work area design to reduce the ergonomics risk and subjective complaints MSDs.

Keywords : REBA, Subjective Complaint MSDs, Workers, Work posture

\section{PENDAHULUAN}

Pembangunan sektor industri baik industri formal maupun informal saat ini merupakan salah satu andalan dalam pembangunan nasional Indonesia yang berdampak positif terhadap penyerapan tenaga kerja, peningkatan pendapatan dan pemerataan pembangunan. Kegiatan industri baik dalam industri dengan skala besar maupun kecil dalam proses produksinya selalu disertai faktor-faktor yang mengandung risiko bahaya sehingga terjadinya kecelakaan kerja maupun penyakit akibat kerja. Penerapan faktor ergonomi sangat penting dilakukan terutama pada sektor industri, yaitu pengetahuan sikap, tata cara dan perencanaan alat kerja yang tepat (Santoso, 2009).

Ergonomi adalah ilmu terapan yang menjelaskan interaksi antara manusia dengan tempat kerjanya. Ergonomi antara lain memeriksa kemampuan fisik para pekerja, lingkungan tempat kerja, dan tugas yang dilengkapi dan mengaplikasikan informasi ini dengan desain model alat, perlengkapan, metodemetode kerja yang dibutuhkan tugas menyeluruh dengan aman (Etchison, 2007).

Gangguan Musculoskeletal adalah gangguan pada bagian otot rangka yang disebabkan karena otot menerima beban statis secara berulang dan terus menerus dalam jangka waktu yang lama dan akan menyebabkan keluhan sendi, ligamen, dan tedon (WHO, 2007) Musculoskeletal Disorders adalah cedera atau keluhan pada jaringan lunak (seperti otot, tedon, ligamen, sendi, dan tulang rawan) dan sistem saraf dimana keluhan ini dapat mempengaruhi hampir seluruh jaringan termasuk saraf dan sarung tendon (Martaleo, 2012).

Faktor-faktor risiko keluhan musculoskeletal menurut Peter (2000), dalam Tarwaka (2010) menjelaskan bahwa, terdapat beberapa faktor yang dapat menyebabkan terjadinya keluhan otot skeletal adalah aktivitas berulang, sikap kerja tidak alamiah, gerakan otot berlebihan, beban, postur janggal, durasi, getaran dan suhu.

Postur kerja merupakan titik penentu dalam menganalisa keefektifan dari suatu pekerjaan. Apabila postur kerja yang dilakukan oleh operator sudah baik dan ergonomis maka dapat dipastikan hasil yang diperoleh oleh operator tersebut akan baik. Akan tetepi bila postur kerja operator tersebut tidak ergonomis maka operator tersebut akan mudah kelelahan. Apabila operator mudah mengalami kelelahan maka hasil pekerjaan yang dilakukan operator tersebut juga akan mengalami penurunan dan tidak sesuai dengan yang diharapkan (Susihono, 2012). Rapid Entire Body Assessment (REBA) adalah sebuah 
metode dalam bidang ergonomi yang digunakan secara cepat untuk menilai postur leher, punggung, lengan, pergelangan tangan, dan kaki seorang pekerja.

Upaya yang dapat dilakukan untuk mengurangi tingkat risiko terjadinya keluhan subjektif musculoskeletal disorders pada pekerja yaitu dengan cara menyesuaikan alat kerja dengan postur kerja pekerja. Sentra Indutri Kendal merupakan salah satu paguyuban di daerah Kendal yang memproduksi tas, dimana setiap aktivitas kerjanya, pekerja berisiko untuk menderita terjadinya Musculoskeletal Disorders (MSDs) terkait dengan masalah ergonomi.

Berdasarkan hasil penelitian sebelumnya yang telah dilakukan di Sentra Industri Tas Kendal pada bagian jahit diketahui bahwa ada hubungan antara postur kerja dengan keluhan nyeri punggung bawah (Low Back Pain) yaitu $\mathrm{p}=0,007$. Postur kerja yang berisiko tinggi terjadinya nyeri punggung bawah sebesar 46\% (Razak, 2014).

Dan berdasarkan hasil studi pendahuluan dalam proses pembuatan tas dari tahap awal hingga tahap akhir, diketahui bahwa pekerja merasakan keluhan nyeri pada beberapa anggota tubuhnya saat bekerja dan setelah bekerja pada bagian leher, pinggang, dan tangan. Hampir seluruh pekerja melakukan aktifitas kerjanya dengan posisi duduk yang terus menerus dan bekerja sesuai jumlah borongan dengan jumlah tas yang harus dibuat tiap orang yaitu minimal 100 tas per minggu, jam kerja panjang dari hari senin hingga sabtu (mulai pukul 08.00-17.00), dan waktu istirahat pekerja tidak diatur, hingga banyak pekerja yang bekerja lebih lama, hingga ada beberapa pekerja yang kembali bekerja dimalam harinya sampai jam 23.00. Hal ini dapat menyebabkan penurunan produktifitas kerja akibat dari keluhan Musculoskeletal Disorders yang dirasakan oleh pekerja.
Dikalukannya penelitian ini adalah untuk menganalisis postur kerja dan keluhan Subjektif Musculoskeletal Disorders (MSDS) pada pekerja di Sentra Industri Kendal.

\section{METODE PENELITIAN}

Penelitian ini merupakan penelitian deskriptif dengan pendekatan cross sectional. Subjek penelitian dipilih dengan cara purposive sampling. 7 dari 32 (total pekerja) pekerja dipilih sebagai responden, yaitu 4 pekerja bagian pola dan 3 bagian gudang di Sentra Industri Tas Kendal. Sampel penelitian dipilih di bagian pola dan gudang oleh karena merupakan bagian pekerjaan yang berisiko untuk terjadi MSDs. 7 responden sudah dapat mewakili sampel yang ada.

Variabel-variabel yang dianalisis dalam penelitian yaitu postur kerja dan keluhan subjektif Musculoskeletal Disorders. Variabel karakteristik responden seperti umur, jenis kelamin, dan masa kerja diperoleh melalui wawancara dengan kuesioner. Variabel postur kerja diperoleh dari hasil observasi atau pengamatan peneliti dan penilaian postur kerja dengan metode REBA yang dinilai dari postur kerja yang telah direkam dan di foto pada pekerja bagian pola dan gudang di Sentra Industri Tas Kendal. Pada pekerjaan di Sentra Industri Tas Kendal ini paling cocok untuk mengukur postur kerja adalah REBA. Sedangkan untuk mengetahui tingkat keluhan subjektif Musculoskeletal Disorders diperoleh dari kuesioner yang berisi 28 item pertanyaan tentang keluhan yang dirasakan di seluruh bagian-bagian tubuh.

\section{HASIL DAN PEMBAHASAN}

\section{Karakteristik Responden}

Sentra Industri Tas Kendal Kecamatan Kangkung melakukan proses 
produksi mulai dari pembuatan pola, pemotongan pola, proses penjahitan potongan-potongan pola, pemasangan aksesoris tas, pengecekan hingga sampai pemasaran. Pada proses ini menimbulkan risiko terjadinya keluhan subjektif Musculoskeletal Disorder, terutama di bagian pola dan gudang.

Karakteristik pekerja pada bagian pola dan gudang di Sentra Industri Tas Kendal yaitu 4 pekerja di bagian pola dan 3 pekerja dibagian gudang. Pekerja ini bekerja selama 6 hari kerja, dari hari senin-sabtu. Jam kerja dimulai dari jam 08.00-17.00 WIB, dengan jam istirahat istirahat yang tidak teratur, bahkan ada pekerja yang melanjutkan pekerjaannya di jam istirahat, dan kembali bekerja dimalam harinya hingga jam 23.00. Semua pekerja berjenis kelamin laki-laki. Usia pekerja minimal 25 tahun dan maksimal 40 tahun. $43 \%$ berusia 33 tahun.
Masa kerja minimal 2 tahun dan paling lama 10 tahun.

Tabel 1. Karakteristik Pekerja bagian pola dan gudang di Sentra Industri Tas Kendal tahun 2017

\begin{tabular}{lc}
\hline KarakteristikResponden & $\mathbf{N = 7}$ \\
\hline Umur (tahun) & \\
25 tahun & $2(29 \%)$ \\
33 tahun & $3(43 \%)$ \\
35 tahun & $1(14 \%)$ \\
40 tahun & $1(14 \%)$ \\
Jenis Kelamin & \\
Laki-laki (\%) & $7(100 \%)$ \\
Perempuan & 0 \\
Masa kerja & \\
3 tahun & $2(29 \%)$ \\
5 tahun & $1(14 \%)$ \\
7 tahun & $2(29 \%)$ \\
10 tahun & $2(29 \%)$ \\
\hline
\end{tabular}

\section{Postur Kerja}

Data terkait analisis postur kerja dapat dilihat pada Tabel 2 .

Tabel 2. Analisis Postur Kerja

\begin{tabular}{lccc}
\hline Nama Responden & \multicolumn{2}{c}{ Hasil pengukuran } & Tindakan \\
\cline { 2 - 4 } & REBA & Tingkat Risiko & \\
\hline Responden 1 & 10 & Tinggi & Segera diperlukan perbaikan \\
Responden 2 & 7 & Sedang & Diperlukan perbaikan \\
Responden 3 & 7 & Sedang & Diperlukan perbaikan \\
Responden 4 & 7 & Sedang & Diperlukan perbaikan \\
Responden 5 & 6 & Sedang & Diperlukan perbaikan \\
Responden 6 & 10 & Tinggi & Segera diperlukan perbaikan \\
Responden 7 & 4 & Sedang & Diperlukan perbaikan \\
\hline
\end{tabular}

Penilaian postur bagian pola dan gudang menggunakan metode REBA menunjukkan hasil tingkat risiko tinggi yang artinya segera diperlukan tindakan sejumlah 2 pekerja (29\%). Penyebab utama dari tingginya nilai akhir REBA pada pekerja bagian pola dan gudang di Sentra Industri Tas Kendal adalah postur kerja statis, dimana pekerja bekerja dalam posisi duduk dalam jangka waktu yang lama tanpa menggunakan alas duduk, leher menunduk secara terus menerus untuk menjangkau objek, punggung membungkuk, pergelangan tangan yang menahan pola pada saat menggambar dan pergerakan tangan kanan yang melakukan gerakan pengguntingan. Sedangkan postur janggal pada pekerja bagian pola disebabkan karena pekerja mengangkat beban terlalu berat tanpa alat bantu. Penilaian postur menggunakan metode REBA menghasilkan tingkat risiko tinggi yang artinya perlu tindakan investigasi dan perubahan sikap segera. 


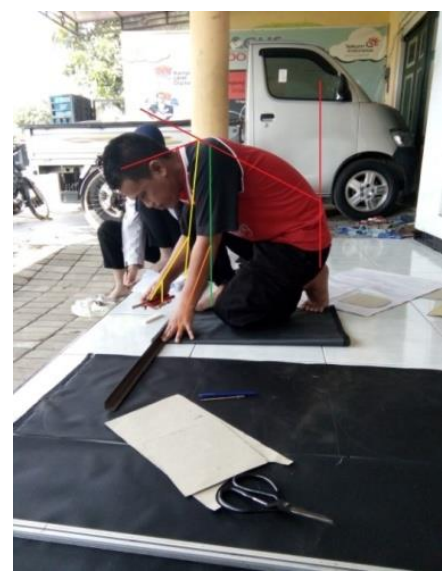

Gambar 1. Pekerja di Bagian Pola

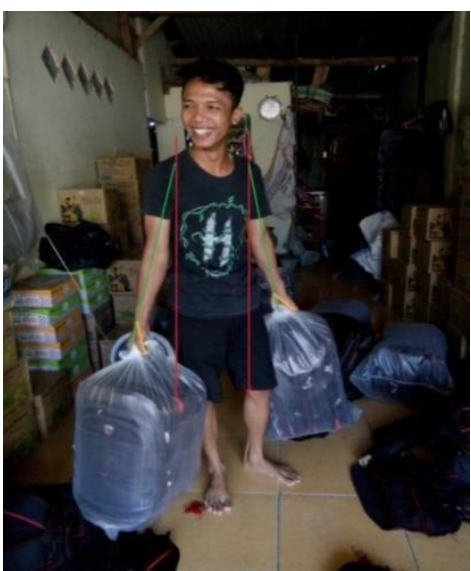

Gambar 2. Pekerja di Bagian Gudang

\section{Keluhan musculoskeletal disorders (MSDs)}

Tabel 3. Distribusi Keluhan MSDs Berdasarkan Bagian Pekerjaan (Pola dan Gudang)

\begin{tabular}{|c|c|c|c|c|c|c|c|c|c|}
\hline \multirow{4}{*}{ NO } & \multirow{4}{*}{ JENIS KELUHAN } & \multicolumn{8}{|c|}{ Keluhan MSDs } \\
\hline & & \multicolumn{4}{|c|}{ Bagian Pola } & \multicolumn{4}{|c|}{ Bagian Gudang } \\
\hline & & \multicolumn{2}{|c|}{$\begin{array}{c}\text { Dalam } 1 \text { tahun } \\
\text { terakhir }\end{array}$} & \multicolumn{2}{|c|}{$\begin{array}{l}\text { Dalam } 7 \text { hari } \\
\text { Terakhir }\end{array}$} & \multicolumn{2}{|c|}{$\begin{array}{c}\text { Dalam } 1 \\
\text { tahun } \\
\text { terakhir }\end{array}$} & \multicolumn{2}{|c|}{$\begin{array}{c}\text { Dalam } 7 \text { hari } \\
\text { terakhir }\end{array}$} \\
\hline & & Ada & $\%$ & ada & $\%$ & Ada & $\%$ & ada & $\%$ \\
\hline 0 & Sakit/kaku di leher bagian atas & 3 & 75 & 1 & 25 & 2 & 67 & 1 & 33 \\
\hline 1 & Sakit/kaku di leher bagian bawah & - & - & 1 & 25 & 2 & 67 & - & - \\
\hline 2 & Sakit di bahu kiri & - & - & 1 & 25 & - & - & - & - \\
\hline 3 & Sakit di bahu kanan & 2 & 50 & 1 & 25 & 3 & 100 & 1 & 33 \\
\hline 4 & Sakit pada lengan atas kiri & - & - & - & - & 1 & 33 & - & - \\
\hline 5 & Sakit di punggung & 2 & 50 & 2 & 50 & 2 & 67 & 1 & 33 \\
\hline 6 & Sakit pada lengan atas kanan & 1 & 25 & - & - & 2 & 67 & 1 & 33 \\
\hline 7 & Sakit pada pinggang & 3 & 75 & - & - & 3 & 100 & - & - \\
\hline 8 & Sakit pada bokong & - & - & 1 & 25 & - & - & - & - \\
\hline 9 & Sakit pada pantat & 2 & 50 & - & - & - & - & - & - \\
\hline 10 & Sakit pada siku kiri & - & - & - & - & - & - & - & - \\
\hline 11 & Sakit pada siku kanan & - & - & - & - & - & - & - & - \\
\hline 12 & Sakit pada lengan bawah kiri & 1 & 25 & - & - & - & - & - & - \\
\hline 13 & Sakit pada lengan bawah kanan & 1 & 25 & - & - & 1 & 33 & 1 & 33 \\
\hline 14 & sakit pada pergelangan tangan kiri & - & - & 1 & 25 & 2 & 67 & - & - \\
\hline 15 & $\begin{array}{l}\text { Sakit pada pergelangan tangan } \\
\text { kanan }\end{array}$ & 3 & 75 & 1 & 25 & 2 & 67 & 1 & 33 \\
\hline 16 & Sakit pada tangan kiri & - & - & - & - & - & - & - & - \\
\hline 17 & Sakit pada tangan kanan & 2 & 50 & 1 & 25 & - & - & - & - \\
\hline 18 & Sakit pada paha kiri & 1 & 25 & - & - & 1 & 33 & - & - \\
\hline 19 & Sakit pada paha kanan & - & - & - & - & 1 & 33 & - & - \\
\hline 20 & Sakit pada lutut kiri & - & - & - & - & 1 & 33 & - & - \\
\hline 21 & Sakit pada lutut kanan & - & - & - & - & 2 & 67 & - & - \\
\hline 22 & Sakit pada betis kiri & 3 & 75 & - & - & - & - & 1 & 33 \\
\hline 23 & Sakit pada betis kanan & - & - & 1 & 25 & - & - & 1 & 33 \\
\hline 24 & Sakit pada pergelangan kaki kiri & - & - & 1 & 25 & - & - & - & - \\
\hline 25 & $\begin{array}{l}\text { Sakit pada pergelangan kaki } \\
\text { kanan }\end{array}$ & - & - & - & - & - & - & - & - \\
\hline 26 & Sakit pada kaki kiri & 2 & 50 & 1 & 25 & 1 & 33 & - & - \\
\hline 27 & Sakit pada kaki kanan & - & - & 1 & 25 & - & - & - & - \\
\hline
\end{tabular}


Tabel 4. Distribusi Keluhan MSDs Berdasarkan Umur pada Pekerja Bagian Pola dan Gudang

\begin{tabular}{|c|c|c|c|c|c|c|c|c|c|}
\hline \multirow{4}{*}{ NO } & \multirow{4}{*}{ JENIS KELUHAN } & \multicolumn{8}{|c|}{ Keluhan MSDs } \\
\hline & & \multicolumn{4}{|c|}{$<30$ tahun } & \multicolumn{4}{|c|}{ 30-40 tahun } \\
\hline & & \multicolumn{2}{|c|}{$\begin{array}{l}\text { Dalam } 1 \text { tahun } \\
\text { terakhir }\end{array}$} & \multicolumn{2}{|c|}{$\begin{array}{l}\text { Dalam } 7 \text { hari } \\
\text { Terakhir }\end{array}$} & \multicolumn{2}{|c|}{$\begin{array}{c}\text { Dalam } 1 \\
\text { tahun } \\
\text { terakhir }\end{array}$} & \multicolumn{2}{|c|}{$\begin{array}{l}\text { Dalam } 7 \text { hari } \\
\text { terakhir }\end{array}$} \\
\hline & & Ada & $\%$ & ada & $\%$ & Ada & $\%$ & ada & $\%$ \\
\hline 0 & Sakit/kaku di leher bagian atas & 1 & 50 & 1 & 50 & 4 & 80 & 1 & 20 \\
\hline 1 & Sakit/kaku di leher bagian bawah & 2 & 100 & - & - & - & - & 2 & 40 \\
\hline 2 & Sakit di bahu kiri & - & - & - & - & - & - & - & - \\
\hline 3 & Sakit di bahu kanan & 1 & 50 & 1 & 50 & 3 & 60 & 1 & 10 \\
\hline 4 & Sakit pada lengan atas kiri & 1 & 50 & - & - & - & - & - & - \\
\hline 5 & Sakit di punggung & 1 & 50 & 1 & 50 & 3 & 60 & 2 & 40 \\
\hline 6 & Sakit pada lengan atas kanan & 1 & 50 & 1 & 50 & 2 & 40 & - & - \\
\hline 7 & Sakit pada pinggang & 2 & 50 & - & - & 4 & 80 & - & - \\
\hline 8 & Sakit pada bokong & - & - & - & - & 1 & 20 & 1 & 20 \\
\hline 9 & Sakit pada pantat & - & - & - & - & 1 & 20 & - & - \\
\hline 10 & Sakit pada siku kiri & - & - & - & - & - & - & - & - \\
\hline 11 & Sakit pada siku kanan & - & - & - & - & - & - & - & - \\
\hline 12 & Sakit pada lengan bawah kiri & - & - & - & - & 1 & 20 & - & - \\
\hline 13 & Sakit pada lengan bawah kanan & 1 & 50 & 1 & 50 & 2 & 40 & - & - \\
\hline 14 & sakit pada pergelangan tangan kiri & 1 & 50 & - & - & 1 & 20 & 1 & 20 \\
\hline 15 & $\begin{array}{l}\text { Sakit pada pergelangan tangan } \\
\text { kanan }\end{array}$ & 1 & 50 & 1 & 50 & 3 & 60 & 2 & 40 \\
\hline 16 & Sakit pada tangan kiri & - & - & - & - & - & - & - & - \\
\hline 17 & Sakit pada tangan kanan & - & - & - & - & 2 & 40 & 1 & 20 \\
\hline 18 & Sakit pada paha kiri & 1 & 50 & - & - & 1 & 20 & - & - \\
\hline 19 & Sakit pada paha kanan & 1 & 50 & - & - & - & - & - & - \\
\hline 20 & Sakit pada lutut kiri & - & - & - & - & 1 & 20 & - & - \\
\hline 21 & Sakit pada lutut kanan & 1 & 50 & - & - & 1 & 20 & - & - \\
\hline 22 & Sakit pada betis kiri & - & - & - & - & 3 & 60 & - & - \\
\hline 23 & Sakit pada betis kanan & - & - & 1 & 50 & - & - & 1 & 20 \\
\hline 24 & Sakit pada pergelangan kaki kiri & - & - & - & - & - & - & 1 & 20 \\
\hline 25 & $\begin{array}{l}\text { Sakit pada pergelangan kaki } \\
\text { kanan }\end{array}$ & - & - & - & - & - & - & - & - \\
\hline 26 & Sakit pada kaki kiri & 1 & 50 & - & - & 2 & 40 & 1 & 20 \\
\hline 27 & Sakit pada kaki kanan & - & - & - & - & - & - & 1 & 20 \\
\hline
\end{tabular}

Tabel 3,4, dan 5 merupakan hasil wawancara dengan kuesioner Nordic Body Map (NBM) pada pekerja bagian pola dan gudang di Sentra Industri Kendal. Berdasarkan lokasi keluhan menunjukkan bahwa pekerja merasakan keluhan pada bagian tubuh pinggang sebanyak 6 pekerja $(86 \%)$ dalam jangka waktu 1 tahun terakhir. Gambaran distribusi keluhan subjektif musculoskeletal disorders (MSDs) yang dirasakan pekerja berdasarkan kategori individu adalah sebagai berikut: a. Pekerja bagian pola sebanyak 3 pekerja $(75 \%)$ dari 4 pekerja merasakan keluhan pada bagian tubuh leher atas, pinggang, pergelangan tangan kanan, dan betis kiri.

b. Pekerja bagian gudang keluhan yang dirasakan oleh pekerja dalam kurun waktu 1 tahun terakhir adalah pada bagian pinggang yaitu sebanyak 3 pekerja (100\%).

c. Pekerja dengan umur $<30$ tahun sebanyak $2(100 \%)$ pekerja merasakan keluhan pada leher bagian atas. 
d. Pekerja yang berumur 30-40 tahun, keluhan yang paling banyak dirasakan dalam kurun waktu 1 tahun terakhir yaitu pada leher bagian atas dan pinggang, sebanyak 4 pekerja (80\%), dan sebanyak 3 pekerja $(60 \%)$ merasakan keluhan pada bagian bahu kanan, punggung, pergelangan tangan kanan, dan betis kiri. e. Pekerja dengan masa kerja $<5$ tahun lebih banyak mengeluhkan pada bagian punggung sebanyak 2 pekerja $(100 \%)$ dalam kurun waktu 1 tahun terakhir.

f. Dan pekerja dengan masa kerja 5-10 tahun lebih banyak mengeluhkan pada bagian bahu sebelah kanan sebanyak 4 pekerja $(80 \%)$ dalam kurun waktu 1 tahun terakhir.

Tabel 5. Distribusi Keluhan MSDs Berdasarkan Masa Kerja Pada Pekerja Bagian Pola dan Gudang di Sentra Industri Tas Kendal Tahun 2017

\begin{tabular}{|c|c|c|c|c|c|c|c|c|c|}
\hline \multirow{4}{*}{ NO } & \multirow{4}{*}{ JENIS KELUHAN } & \multicolumn{8}{|c|}{ Keluhan MSDs } \\
\hline & & \multicolumn{4}{|c|}{$<5$ tahun } & \multicolumn{4}{|c|}{ 5-10 tahun } \\
\hline & & \multicolumn{2}{|c|}{$\begin{array}{l}\text { Dalam } 1 \text { tahun } \\
\text { terakhir }\end{array}$} & \multicolumn{2}{|c|}{$\begin{array}{c}\text { Dalam } 7 \text { hari } \\
\text { Terakhir }\end{array}$} & \multicolumn{2}{|c|}{$\begin{array}{l}\text { Dalam } 1 \\
\text { tahun } \\
\text { terakhir }\end{array}$} & \multicolumn{2}{|c|}{$\begin{array}{c}\text { Dalam } 7 \text { hari } \\
\text { terakhir }\end{array}$} \\
\hline & & Ada & $\%$ & Ada & $\%$ & Ada & $\%$ & Ada & $\%$ \\
\hline 0 & Sakit/kaku di leher bagian atas & 1 & 50 & 1 & 50 & 4 & 80 & 1 & 20 \\
\hline 1 & $\begin{array}{l}\text { Sakit/kaku di leher bagian } \\
\text { bawah }\end{array}$ & 1 & 50 & - & - & 1 & 20 & 2 & 40 \\
\hline 2 & Sakit di bahu kiri & - & - & - & - & 1 & 20 & - & - \\
\hline 3 & Sakit di bahu kanan & 1 & 50 & 1 & 50 & 3 & 60 & 1 & 20 \\
\hline 4 & Sakit pada lengan atas kiri & & - & - & - & 1 & 20 & - & - \\
\hline 5 & Sakit di punggung & 1 & 50 & 1 & 50 & 3 & 60 & 2 & 40 \\
\hline 6 & Sakit pada lengan atas kanan & 1 & 50 & 1 & 50 & 2 & 40 & - & - \\
\hline 7 & Sakit pada pinggang & 2 & 100 & - & - & 3 & 60 & - & - \\
\hline 8 & Sakit pada bokong & - & - & - & - & - & & 1 & 20 \\
\hline 9 & Sakit pada pantat & - & - & - & - & 1 & 20 & - & - \\
\hline 10 & Sakit pada siku kiri & - & - & - & - & 1 & 20 & - & - \\
\hline 11 & Sakit pada siku kanan & - & - & - & - & - & - & - & - \\
\hline 12 & Sakit pada lengan bawah kiri & 1 & 50 & - & - & - & - & - & - \\
\hline 13 & $\begin{array}{l}\text { Sakit pada lengan bawah } \\
\text { kanan }\end{array}$ & - & - & 1 & 50 & 2 & 40 & - & - \\
\hline 14 & $\begin{array}{l}\text { sakit pada pergelangan tangan } \\
\text { kiri }\end{array}$ & - & - & 1 & 50 & 2 & 40 & - & - \\
\hline 15 & $\begin{array}{l}\text { Sakit pada pergelangan tangan } \\
\text { kanan }\end{array}$ & 1 & 50 & 1 & 50 & 3 & 40 & 2 & 40 \\
\hline 16 & Sakit pada tangan kiri & - & - & - & - & - & - & - & - \\
\hline 17 & Sakit pada tangan kanan & - & - & - & - & 2 & 40 & - & - \\
\hline 18 & Sakit pada paha kiri & - & - & - & - & 1 & 20 & - & - \\
\hline 19 & Sakit pada paha kanan & - & - & - & - & 1 & 20 & - & - \\
\hline 20 & Sakit pada lutut kiri & - & - & - & - & 1 & 20 & - & - \\
\hline 21 & Sakit pada lutut kanan & 1 & 50 & - & - & 1 & 20 & - & - \\
\hline 22 & Sakit pada betis kiri & 1 & 50 & 1 & 50 & 2 & 40 & - & - \\
\hline 23 & Sakit pada betis kanan & - & - & 1 & 50 & - & - & 1 & 20 \\
\hline 24 & $\begin{array}{l}\text { Sakit pada pergelangan kaki } \\
\text { kiri }\end{array}$ & - & - & 1 & 50 & - & - & - & - \\
\hline 25 & $\begin{array}{l}\text { Sakit pada pergelangan kaki } \\
\text { kanan }\end{array}$ & - & - & - & - & - & - & - & - \\
\hline 26 & Sakit pada kaki kiri & - & - & 1 & 50 & 2 & 40 & - & - \\
\hline 27 & Sakit pada kaki kanan & - & - & - & - & - & - & 1 & 20 \\
\hline
\end{tabular}


Penyebab utama keluhan subjektif Musculoskeletal Disorders yang dirasakan pekerja bagian pola dan gudang di Sentra Industri Tas Kendal adalah postur janggal, postur kerja statis, dimana pekerja bekerja dengan posisi duduk terus menurus tanpa menggunakan alas duduk, leher menunduk untuk menjangkau objek, punggung membungkuk, dan pergelangan tangan kanan yang melakukan gerakan pengguntingan pola.

Pemilik perusahaan sebaiknya memperhatikan masalah-masalah ergonomi yang terkait dengan postur kerja dengan tujuan untuk mengurangi tingkat keluhan subjektif Musculoskeletal Disorders pada pekerja bagian pola dan gudang di Sentra Industri Tas Kendal.

\section{KESIMPULAN}

Setelah dilakukan semua tahaptahap penelitian mulai dari pengumpulan data, pengolahan data, analisis data, penyajian hasil penelitian dan pembahasan dapat disimpulkan bahwa pekerja di Sentra Industri Tas Kendal pada bagian pola dan gudang hasil akhir penilaian menggunakan metode REBA yaitu tingkat risiko tinggi, sehingga perlu tindakan investigasi dan perubahan segera.

Penelitian terkait gambaran keluhan subjektif musculoskeletal disorders yang dirasakan pekerja pada aktifitas bagian pola dan gudang di Sentra Industri Tas Kendal, tahun 2017adalah postur janggal, postur statis, durasi, dan frekuensi.

Dalam rangka mengurangi tingkat keluhan subjektif musculoskeletal pada pekerja bagian pola dan gudang di Sentra Industri Tas Kendal, disarankan bagi pemilik perusahaan industri informal pembuatan tas tersebut untuk memberikan penyuluhan guna mengurangi tingkat risiko ergonomi. Mendesain beberapa area kerja yang disesuaikan dengan pekerja sehingga dapat mengurangi postur janggal.

Pada aktifitas pembuat pola dan potong bekerja dalam posisi duduk tanpa alas, dapat ditambah menggunakan alas berupa busa atau bantal bekas agar lebih nyaman saat bekerja. Pada aktifitas di gudang pekerja mengangkat barangbarang secara manual, sebaiknya menggunakan alat bantu berupa troli.

\section{DAFTAR PUSTAKA}

Abdillah. (2013). Analisis Pada Postur Kerja Dengan Metode Rapid Upper Limb Assessment (RULA) Pada Pekerja Kuli Angkut Buah Di Agen "Ridho Ilahi" Pasar Johar Kota Semarang. Jurnal FKM Universitas Diponegoro. Vol. 2, No. 1 tahun 2003.

Ariani. (2010). Analisis Mesin Untuk Mengurangi Cartigue Akibat Kerja Pada Bagian Air Traffic Control (ATC) Di PT. Angkasa Rula II Polonia Medan. Jurnal Dinamis. Vol. II no. 6 Januari 2010.

Arikunto, S. (2013). Prosedur Penelitian: Suatu Pendekatan Praktik. Renika Cipta, Jakarta.

Kemenkes RI. (2015). Rencana Strategi Kmentrian Kesehatan Tahun 2015-2019.. Kementrian Kesehatan RI, Jakarta.

Kuorinka, I., Jonsson, B., Kilbom, A., Vinterberg, H., Biering-Sørensen, F., Andersson, G., \& Jørgensen, K. (1987). Standardized Nordic Questionnaire For The Analysis Of Musculoskeletal Symptoms. Appl Ergon. 1987 Sep;18(3):233-7. 
Martaleo. (2012). Perbandingan Penilaian Risiko Ergonomi dengan Metode REBA dan QEC (Studi Kasus Pada Kuli Angkut Terigu). Jurnal Simposium Nasional RAPI XI FT UMS. ISSN: 1412-9612: 157-163.

Martha, J. (2009). Gangguan Musculoskeletal. EGC, Jakarta.

Mas'idah, Fatmawati \& Ajibta. (2009). Analisis Manual Material Handling (MMH) dengan Menggunakan Metode Biomekanika untuk Mengidentifikasi Resiko Cidera Tulang Belakang (Musculoskeletal Disorder). Jurnal Sultan Agung. 45 (119): 37-56.

Nursatya. (2008). Resiko MSDs Pada Pekerja di Bidang Komputerisasi. FKM UI, Jakarta.

Nurliah. (2012). Analisis Risiko Musculoskeletal Disorders (Msds) Pada Operator Forklift di PT, LLI Tahun 2012. Universitas Indonesia.

OSHA. (2008). Ergonomics: The Study of Work. Departement of Labour, U.S.

Razak. (2014). Hubungan Antara Postur Kerja Dengan Keluhan Nyeri Punggung Bawah Pada Pekerja Di Sentra Industri Pembuat Tas Truko Kabupaten Kendal tahun 2014.Skripsi. Kendal: Sekolah Tinggi Ilmu Kesehatan (STIKes) Kendal.

Rismaningrum. (2015). Faktor-faktor yang berhubungan dengan keluhan Musculoskeletal pada pekerja genteng di desa meteseh kecamatan boja kabupaten kendal. Skripsi. Kendal: Sekolah Tinggi Ilmu Kesehatan (STIKes) Kendal.

Rochman, Astuti \& Miftahudin, (2012). Usulan Perbaikan Terhadap Aktivitas Penurunan Pasir Di Depo Pasir Makmur Menggunakan Pendekatan Postur Kerja Dan Assessment Terhadap Fisiologi Kerja (Studi Kasus: Depo Pasir Makmur, Surakarta). Prosiding Seminar Nasional Aplikasi Sains \& Teknologi (SNAST) Periode III: Yogyakarta

Sujoso, A.D.P., Fani, M., Fitria, A. \& Ikmala, R. (2010). Analisis egonomi pada pekerja laundri. Bagian Kesehatan Lingkungan dan Kesehatan Keselamatan kerja Fakultas Kesehatan Masyarakat Universitas Jember. Korespondensi: J1 Kalimantan I/93 Kampus Tegal Boto, Jember.

Susanto, G. (2013). Ergonomi, Manusia, Peralatan dan Lingkungan. Prestasi Pustaka, Jakarta.

Susihono, W. (2013). Penerapan Sistem Manajemen K3 dan identifikasi potensi bahaya kerja (studi kasus di PT. LTX Kota Cilegon - Banten). Universitas Sultan Ageng Tirtayasa. Spektrum Industri, Jurnal Ilmiah Pengetahuan \& Penerapan Teknik Industri 2013, Vol. 11, No. 2, 117 - 242. ISSN : 1963-6590

Suma'mur. (2009). Higine Perusahaan Dan Kesehatan Kerja (Hiperkes). Tri Tunggal Tata Fajar, Jakarta.

Tarwaka. (2010). Dasar-Dasar Pengetahuan Ergonomi Dan Aplikasi Di Tempat Kerja. Harapan Press, Surakarta.

Tarwaka. (2014). Ergonomi Industri; Dasar-Dasar Pengetahuan Ergonomi Dan Aplikasi Di Tempat Kerja. Harapan Press, Surakarta.

Torik. (2015). Analisis Postur Dengan Metode RULA Untuk Kerja Administrasi. SINERGI. Vol.19, No.1 Februari 2105.

Wakhid. (2009). Analisis Postur Kerja Pada Aktivitas Pengangkutan Buah Kelapa Sawit Dengan Menggunakan Metode Rapid Entire Body Assessment (Reba). Program Studi Teknik Industri Fakultas Teknik, Universitas Dian Nuswantoro. Semarang. 